\begin{tabular}{|c|c|c|}
\hline $4 F$ & $\begin{array}{l}\text { European Association for the } \\
\text { Development of Renewable Energies, Environment } \\
\text { and Power Quality (EA4EPQ) }\end{array}$ & $\begin{array}{l}\text { International Conference on Renewable Energies and Power Quality } \\
\text { (ICREPQ'12) } \\
\text { Santiago de Compostela (Spain), 28th to 30th March, } 2012\end{array}$ \\
\hline
\end{tabular}

\title{
Educational Architecture: Evaluation and Proposals for the Energy Performance of the Building Envelope.
}

\author{
A. Michael ${ }^{1}$ \\ ${ }^{1}$ Department of Architecture, Faculty of Engineering, University of Cyprus \\ Kallipoleos St. 75, P.O.Box 20567, 1678 Nicosia, Cyprus \\ Phone/Fax number: +357 2289 2280, e-mail: aimilios@ucy.ac.cy
}

\begin{abstract}
Public educational buildings require a high level of indoor comfort conditions to be achieved for their users. The vast majority of educational buildings in Cyprus consist of typical typologies and construction characteristics. The designs show significant similarities, extensive standardization of building components and construction methods and a reliance on previously tested building models. The intent of this paper is to investigate the energy performance of a typical classroom, as well as to evaluate various methods for improving energy performance, based on construction interventions.

For the investigation of the energy performance of the case studies, a standard methodology for the calculation of the energy performance of buildings in Cyprus has been applied, based on the directive 2002/91/EC for the energy classification of buildings (software SBEMcy v3.3.d). The base model used for the investigation is examined according to the four orientations and the four climatic zones of Cyprus.
\end{abstract}

The analysis consists of a comparison of the energy consumption and carbon dioxide footprint of each building model to the respective energy- and environmental parameters of a reference building. Construction improvement strategies for the energy performance of the educational space (thermal insulation) and other construction interventions (buffer zones, solar spaces) are examined.

The results of the analysis for each construction or architectural intervention are then compared to allow for an evaluation of the respective contribution to the decrease in energy demands and carbon dioxide emissions, as to the typical classroom in its present state.

\section{Key words}

Educational Buildings, Energy Consumption, Construction and Architectural Improvement Strategies.

\section{Introduction}

The school building is the first contact between a person and a public building and it is also a demanding space regarding the comfort levels $[1,2,3]$. The majority of educational buildings in Cyprus consists of typical typologies and construction characteristics. The buildings were mainly designed by the Technical Services Authorities of the Ministry of Education and Culture of Cyprus. The designs show significant similarities, extensive standardization of building components and construction methods and a reliance on previously tested building models. The architectural design of a school building arises without any speculation concerning the climatic conditions, the appropriate orientation and the arrangement of openings in relation to the prevailing local wind flow [4].

The typical school building's structural system is made of reinforced concrete, referring to the majority of the buildings in Cyprus. The structural design of typical school buildings presents regularity and a significant level of standarisation. The columns of the building are placed on a $7 \times 4 \mathrm{~m}$ grid. Classrooms mainly consist of two construction modulus, resulting to slightly rectangular sections with dimensions of approximately 7 x $8 \mathrm{~m}$ and 50 to $60 \mathrm{~m}^{2}$ in area. [4]. The walls are made of local perforated bricks of dimensions $20 \times 30 \times 10 \mathrm{~cm}$. The overall width of the brickwork is $25 \mathrm{~cm}$ including coating. Typical school buildings do not have thermal insulation within the exterior walls, brickwork, props or stilts. Openings are usually filled with aluminum frames, rarely with metal frames, whereas in all cases a single glass pane is used [4]. 


\section{Energy Performance of School Premises}

This study examines the energy performance of classrooms in typical school premises, as well as the methods of improvement of energy performance through construction interventions. The Methodology of Calculation of the Building Energy Efficiency, developed according to the Energy Performance of Buildings, is employed in order to investigate the energy efficiency of the school premises [5]. The calculation of energy consumption and energy categorization of the buildings is accomplished with the use of the calculation software SBEMcy v3.3.d. [6].

A classroom in a two-storey linear row of classes has been selected for the investigation of the energy efficiency of typical school buildings. The room of investigation is situated in central position within the building, with rooms (heated areas) at the two sides. There is also a classroom (heated area) on the ground floor. The exposed elements to the climate changes are the classroom roof and the two large sides including the openings (the main openings and the skylight), Fig.1,2.

The decision for the central classroom has been made by taking into consideration that the majority of classrooms are in central positions within the buildings. The decision of the particular classroom on the first floor allows for the investigation of energy efficiency resulting from thermal insulation of the roof, architectural interventions as well as geometry interventions to the walls of the open corridors.

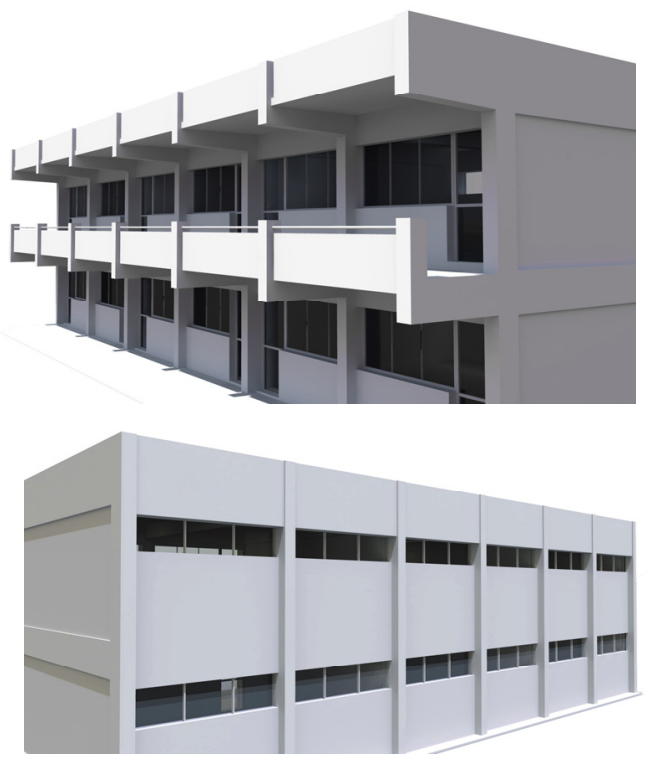

Fig. 1,2. View of façade (main openings) and back view (skylights) of a typical school building.

For the investigation of the energy efficiency of a typical classroom, a model of the building's geometrical characteristics has been created with the SBEMcy v3.3.d software [6]. The specifications of the reference building are used in order to assess the particular building model.
According to the Methodology of Calculation of Building Energy Efficiency, the reference building has the same dimensions of exterior walls and functions, as well as the same climatic zone and orientation as the actual building. Concerning the reference building, the construction characteristics of exterior walls are determined by the Energy Service of the Ministry of Commerce, Industry and Tourism [5].

The assessment of the energy efficiency of the classroom at its present state is based on the comparative assessment of energy consumption for heating and carbon dioxide emissions, with the respective figures of energy consumption and emissions of the reference building. A series of construction interventions is suggested for the improvement of energy efficiency of the typical classroom. The contribution of these interventions in relation to the energy attitude of the typical classroom is assessed based on the comparative presentation of energy consumption and carbon dioxide emissions of each intervention with the respective figures of a typical classroom at its present state.

\section{Assessment of Classroom Energy Efficiency}

The assessment of the typical classroom's energy efficiency at its present state is based on its energy consumption for heating and carbon dioxide emissions at the four different climatic zones and orientations. Compared to the energy consumption for heating of the reference building, the energy consumption of a typical classroom with south orientation at its present state is presented rather high in all climatic zones, Fig. 3.

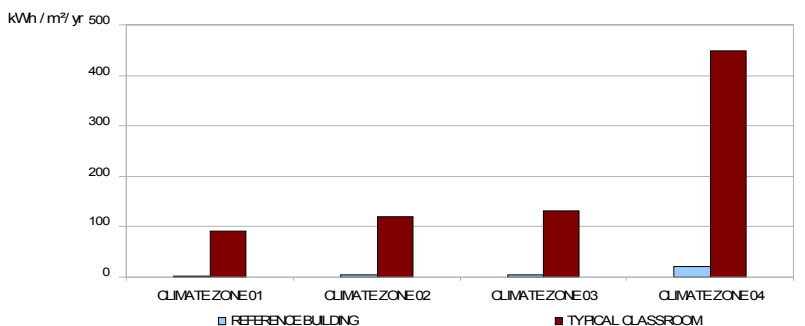

Fig. 3. Comparative graphic presentation of energy consumption for heating per square meter per running year of the reference building and a typical classroom at its present state with south orientation, at the different climatic zones [6].

Regarding the carbon dioxide emissions per square meter, per running year of the typical classroom at its present state, these are presented in relation to the thermal consumption. A gradual increase is presented from climatic zone 01 to climatic zone 04 , and the same sequence with the energy consumption for heating is followed. Therefore the energy performance of typical classrooms at their present state is considered significantly unfavorable. The energy demands for heating needs show a significant deviation in relation to these of the reference building. As a result, the running of the school building is significantly energy-consuming and results to negative environmental consequences. 


\section{Assessment of Improvement of Classrooms Energy Efficiency Through Construction Interventions}

The assessment of construction interventions in the classrooms is based on the comparative assessment of energy consumption for heating and carbon dioxide emissions in relation to the respective parameters of the typical classroom at its present state and the reference building. Furthermore, a comparative assessment of energy demands and carbon dioxide emissions is made for the different climatic zones and orientations.

\section{A. Construction interventions}

Thermal insulation of the roof and the exterior walls, as well as the heat insulating protection of external openings through the replacement of single glazing with Low-E double glazing are recommended for the complete thermal insulation of the building envelope.

1) Typical school room with thermal insulation of the roof. The placement of styrofoam with a thickness of $50 \mathrm{~mm}$ at the roof of the classroom and the dry placement of cement flagstones above the surface of thermal insulation is recommended in order to consolidate and protect the insulation. Thermal insulation installation does not affect the present humidity buffering and neither the construction's overall effective heat capacity.

2) Typical classroom with thermal insulation of the roof and the exterior walls. The thermal insulation of the roof, as it is described above and additionally the thermal insulation of the exterior walls with the use of stone wool in drywall is recommended.

3) Typical classroom with thermal insulation of building envelope. Thermal insulation of the roof and the exterior walls, as described above, as well as the heat insulating protection of external openings through the replacement of single glazing with Low-E double glazing are recommended for the complete thermal insulation of the building envelope.

\section{B. Results of construction interventions}

According to the above, the thermal insulating protection of the building envelope is proven to be a significant parameter to the improvement of a typical classroom's energy efficiency. The energy consumption for heating decrease is almost proportional to each one of the additional heat insulation interventions, as presented in Fig. 4.

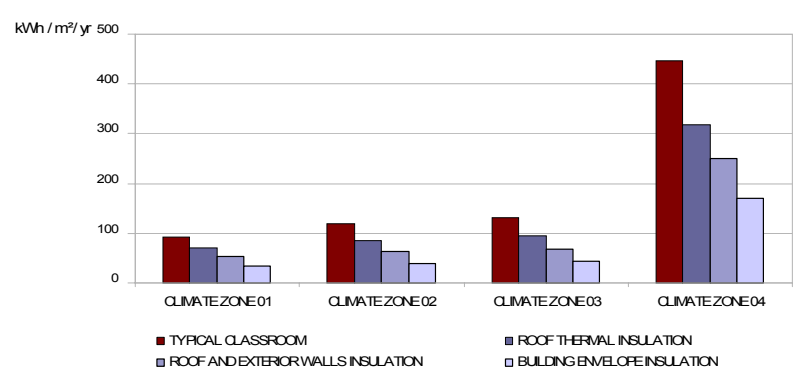

Fig. 4. Comparative graph of energy consumption for heating decrease of the typical classroom for different interventions in comparison to its present state for south orientation [6].

The classification of carbon dioxide emissions and the respective percentage of decrease are presented in relation to the classification of energy consumption for heating, Fig. 5. However, compared to the decrease of energy consumption for heating, lower rates of emission decrease are noted, given that the energy consumption for heating consists only of the factors that cause carbon dioxide emissions (lighting and hot water consumption). Significantly lower emission rates appear in colder climatic zones. Higher percentages of consumption refer to the energy consumption for heating.

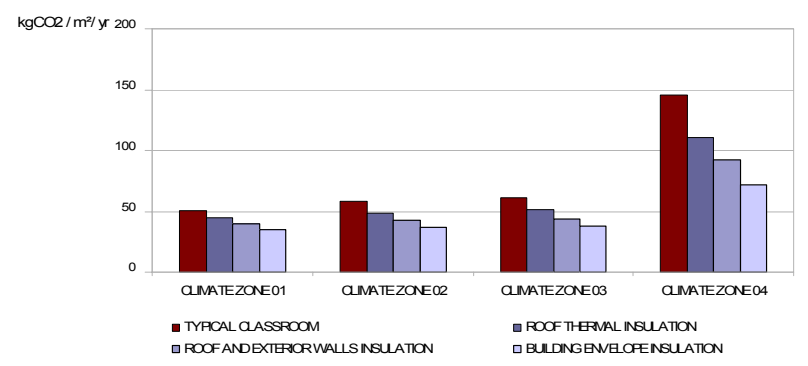

Fig. 5. Comparative graph of carbon dioxide emission decrease of a typical classroom for different interventions, in comparison to its present state for south orientation [6].

\section{Assessment of Improvement of The Energy Efficiency of Classroom Through Architectural Interventions}

A series of architectural interventions is recommended for the improvement of the energy efficiency of a typical classroom. The contribution of these interventions to the energy performance of the typical classroom is assessed based on the comparative presentation of energy consumption for heating and carbon dioxide emissions of each intervention, with the respective figures of energy consumption for heating and emissions of the typical classroom at its present state. 


\section{A. Creation of buffer zones in typical classrooms with north orientation}

The creation of buffer zones in typical classrooms with north orientation is suggested due to the considerable thermal loss that develops with north orientation in all

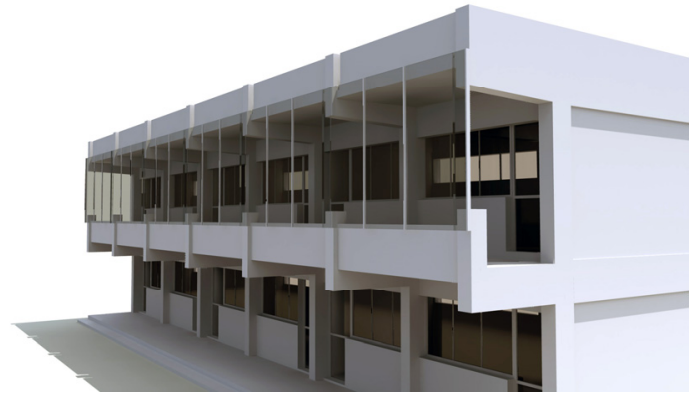

Fig. 6. View of the north side of school building with buffer zone.

climatic zones, in comparison to the other orientations, resulting from the limited direct solar effect, Fig. 6.

The placement of aluminium frames with single safety glass along the open corridor is proposed in order to create a non-thermal zone at the front of the north openings of the typical classroom.

The energy demands of a typical classroom with north orientation and buffer zones are presented in Table 1. The energy consumption for heating is gradually increased from climatic zone 01 to climatic zone 04 . The energy consumption of heating in climatic zone 01 is 92.72 $\mathrm{KWh} / \mathrm{m}^{2} / \mathrm{yr}$, in climatic zone $02,113.30 \mathrm{KWh} / \mathrm{m}^{2} / \mathrm{yr}$ and in climatic zone $03,120.48 \mathrm{KWh} / \mathrm{m}^{2} / \mathrm{yr}$. The climatic zones 02 and 03 have similar energy consumption for heating. Finally in climatic zone 04, a much higher rate of energy consumption for heating is noted, which reaches $401.95 \mathrm{KWh} / \mathrm{m}^{2} / \mathrm{yr}$.

The energy consumption rates for heating decrease in relation to the respective rates of a typical classroom at its present state. The rates of the energy consumption for heating decrease fluctuate from $2.53 \%$ in climatic zone 01 to $11.32 \%$ in climatic zone 04 . Concluding, the creation of buffer zones has a significant effect to the colder climatic zones (table 1).

Table 1: Table of energy consumption for heating per square meter, per running year for a typical classroom with buffer zones to the north in the different climatic zones [6].

\begin{tabular}{|c|c|c|c|c|}
\hline $\mathrm{KWh} / \mathrm{m} 2 / \mathrm{yr}$ & $\mathrm{CZ} 01$ & $\mathrm{CZ} 02$ & $\mathrm{CZ} 03$ & $\mathrm{CZ} 04$ \\
\hline $\mathrm{NORTH}$ & 92.72 & 113.30 & 120.48 & 401.95 \\
\hline$\%$ & -2.53 & -7.29 & -9.79 & -11.32 \\
\hline
\end{tabular}

Carbon dioxide emission is proportional to thermal consumption. A gradual increase is presented from climatic zone 01 to zone 04 and rates fluctuate from $50.76 \mathrm{Kg} \mathrm{CO} 2 / \mathrm{m}^{2} / \mathrm{yr}$ in climatic zone 01 , to $133.02 \mathrm{Kg}$ $\mathrm{CO} 2 / \mathrm{m}^{2} / \mathrm{yr}$ in climatic zone 04 .
The decrease in the rates of carbon dioxide emission fluctuates from $1.25 \%$ in climatic zone 01 , to $9.31 \%$ in climatic zone 04 . The decrease in the rates of carbon dioxide emissions is more significant in colder climatic zones. For climatic zones 02 and 03 the decrease in rates of carbon dioxide emission is similar.

Therefore creating buffer zones in typical classrooms with north orientation, improves the energy performance of classrooms with more significant effects in colder climatic zones, where the rate of decrease reaches $9.47 \%$ in contrast to the rate of a typical classroom at its present state. Furthermore, the creation of buffer zones offers a range of advantages related to the creation of a nonthermal space of detonation, to the sound-proof improvement of the classroom etc.

\section{B. Creation of a solar space in typical classrooms with south orientation}

The creation of solar space in typical classrooms with south orientation is proposed due to the significant solar benefits of south orientation. Consequently, the maximization of thermal collection, storage and transportation of solar energy into the internal of functional spaces and particularly into the classrooms are provided. The issue of deactivating the function of the solar space during cooler periods is provided by opening parts of the glass openings Fig. 7, 8 .

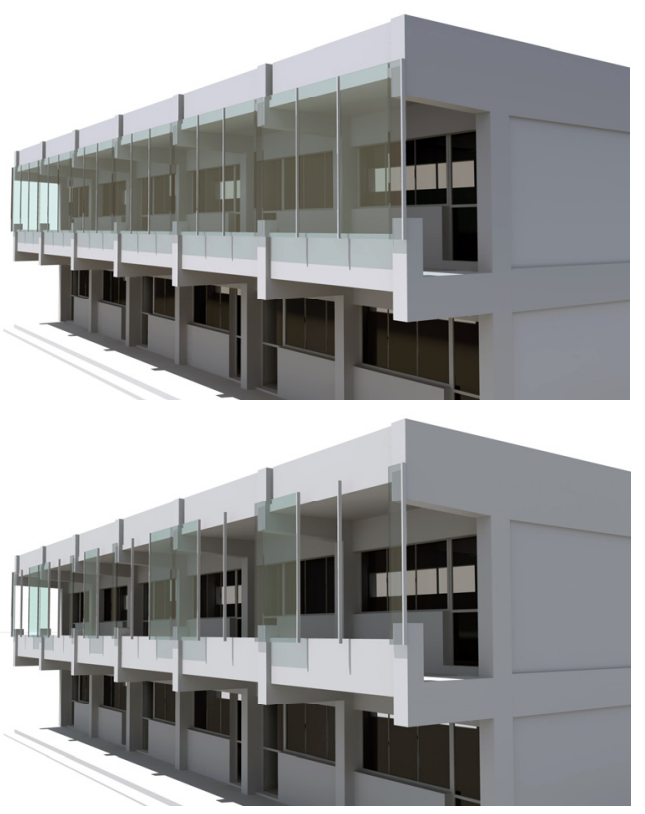

Fig. 7, 8. View of solar space of typical classrooms with south orientation, during the winter and summer periods respectively.

The placement of aluminum frames with single safety glass along the opening corridor creating a set, non thermal zone at the front of the south openings of the classroom is structurally recommended in order to convert the corridor into a set, non thermal space. 
The appropriate design of aluminum frames enables the opening part of the glass window and therefore deactivates the solar disposition during hot periods.

The energy demands arising from the energy consumption for heating of a typical classroom of south orientation with solar space annexation are presented in Table 2. The energy consumption for heating per square meter, per running year of the reference building is gradually increased from climatic zone 01 to climatic zone 04 . In fact, the energy consumption of heating in climatic zone 01 accounts to $68.88 \mathrm{KWh} / \mathrm{m}^{2} / \mathrm{yr}, 83.62$ $\mathrm{KWh} / \mathrm{m}^{2} / \mathrm{yr}$ in climatic zone 02 and $93.38 \mathrm{KWh} / \mathrm{m}^{2} / \mathrm{yr}$ in climatic zone 03 . Climatic zones 02 and 03 have similar energy consumption. Finally, much higher rates of energy consumption are noted in climatic zone 04 and the respective rate of energy consumption is 311.16 $\mathrm{KWh} / \mathrm{m}^{2} / \mathrm{yr}$.

Energy consumption for heating rates appears particularly limited in relation to the respective rates of a typical classroom at its present state. The percentage of energy consumption for heating decrease fluctuates from $25.42 \%$ in climatic zone 01 to $30.51 \%$ in climatic zone 04, Table 2.

Table 2: Table of energy consumption for heating per square meter, per running year of typical classroom with solar space with south orientation at the different climatic zones [6].

\begin{tabular}{|c|c|c|c|c|}
\hline $\mathrm{KWh} / \mathrm{m} 2 / \mathrm{yr}$ & $\mathrm{CZ} 01$ & $\mathrm{CZ} 02$ & $\mathrm{CZ} 03$ & $\mathrm{CZ} 04$ \\
\hline $\mathrm{NORTH}$ & 68.88 & 83.62 & 93.38 & 311.16 \\
\hline$\%$ & -25.42 & -30.12 & -28.70 & -30.51 \\
\hline
\end{tabular}

Carbon dioxide emissions appear proportional to thermal consumption. A gradual increase is marked from climatic zone 01 to climatic zone 04 and rates fluctuate from $43.90 \mathrm{Kg} \mathrm{CO} 2 / \mathrm{m}^{2} / \mathrm{yr}$ in climatic zone 01 to $108.34 \mathrm{Kg}$ $\mathrm{CO} 2 / \mathrm{m}^{2} / \mathrm{yr}$ to climatic zone 04 . The decrease at the rates of carbon dioxide emission fluctuates from $13.34 \%$ in climatic zone 01 to $25.39 \%$ to climatic zone 4 . The decrease of the rates of carbon dioxide emission is more significant in colder climatic zones. For climatic zones 02 and 03 the rates of decrease appear to be similar.

The creation of solar spaces in typical classrooms with south orientation, significantly improves the energy performance of typical classrooms with an average decrease of $28.69 \%$ on respective energy demands compared to that of a typical classroom at its present state.

The appropriate design of glass frames ensures the deactivation of the solar space function during cooler periods. Furthermore, the creation of a solar space provides advantages related to the creation of a nonthermal detonation, the improvement of sound proofing, etc.

\section{Conclusions}

The energy consumption for heating of a typical classroom appears rather high. Improvement methods of the classroom's energy performance may be sought with construction- and architectural interventions. Construction interventions refer to methods of thermal insulation protecting the building cover. They are also significant for the improvement of the classroom's energy efficiency. Consequently the energy demands for heating appear rather limited in comparison to those for the typical classroom.

However, uncontrolled ventilation is the primary cause of thermal loss resulting to energy loss (negative effects for the energy benefits), as a result of the construction interventions. Therefore, the installation of necessary ventilation during winter with the use of controlled technical ventilation is suggested. A technical system of ventilation with heating inverter reduces the thermal losses. The use of technical ventilation with the use of $\mathrm{CO}_{2}$ concentration censors ensures the necessary air circulation and the appropriate air quality inside the space.

Architectural interventions refer to the creation of buffer zones in typical classrooms with south orientation and to the creation of solar spaces in typical classrooms with south orientation. In the case of solar spaces, the use of pre-heated air is proposed for the ventilation of the classrooms. These methods significantly improve the energy performance of typical classrooms. Additionally, such interventions offer a range of advantages related to the creation of a non-thermal detonation space, the improvement of classroom sound proofing, etc.

The recommended measures and improvement strategies, apart from the limitation of energy demands and the positive environmental effects, ensure also the improvement of comfort conditions as well as the living conditions of the users of the school building $[3,7]$.

\section{References}

[1] K. Axarli - Antoniou, Energy design of building envelope and solar gain for school buildings in Greece, Doctoral Thesis, School of Civil Engeerers, Aristotle University of Thessaloniki, Thessaloniki, 1995.

[2] E. Evagglinos, G. Kontoroupis, E. Maistrou, Assesment of solar heating methods for school buildings, School of Architecture, National Technical University of Athens, Athens, 1978.

[3] C.R.E.S., Guidelines for Thermal - Visual Comfort and Energy Conservation in Puplic Buildings, Center for Renewable Energy Sourses, European Commision, Directorate General for Energy (DG XVII), Athens, 2002. 
[4] A. Michael, Overall Comfort Conditions and Energy Performance of School Premises in Cyprus, Doctoral Thesis, School of Architecture, National Technical University of Athens, Athens, 2011.

[5] Methodology of Calculation of Building Energy Efficiency, Energy Service, Ministry of Commerce, Industry and Tourism, Nicosia, 2009.
[6] SBEMcy v3.3.d, Building Energy Efficiency Software, Infotrend Innovations, BRE, Energy Service, Ministry of Commerce, Industry and Tourism, Nicosia, 2009.

[7] S. Yannas, Design of educational buildings, Volume 1: Primer, Environmental and Energy Studies Programme, Architectural Association Graduate School, AA Publications, London, 1994. 